whose point of view is, of course, entirely different, seems to be satisfied with the Act and to find it administratively workable. A suggestion made to the Minister in 1961 that the working of the Act should be reviewed and scrutinized was not acceptable. But I have, I think, given reasons why under the present arrangements the diagnosis of industrial dermatitis is commonly made on inadequate data and may depend materially upon the personality of the doctor and upon unconscious motivation deriving, for example, from the circumstances of the examination and from political expediency. Not surprisingly, there is a great deal of wrong certification with often deplorable results, leading to unnecessary hardship and obstructing the progress of our understanding of industrial disease.

\section{Summary}

The points which are of importance in the diagnosis of industrial dermatitis are enumerated, and it is shown that each of these is open to differences of interpretation. The most important information is to be obtained by prolonged observation of the case continued over a period of several or many months during change or interruption of work, and if these occur during successive attacks.

It is unfortunate that, for the purposes of National Health Insurance, certification needs to be made without delay before any substantial period of observation. Because of this the diagnosis has to be made prematurely and on inadequate evidence. In these circumstances the personal bias of the doctor may play an important part, and it seems that in practice the diagnosis of industrial dermatitis is made far too often. It is suggested that the situation would be remedied if Industrial Disease Benefit were paid at the same rate as Sicinness Benefit. The diagnusis could then be made without hurry and after due observation and consideration. The result would be more accurate certification and a more just distribution of the financial benefits paid for incapacity.

\section{REFERENCES}

Bettley, F. R. (1964). Brit. med. F., 2, 151.

Eysenck, H. J. (1954). The Psychology of Politics. Routledge and Kegan Paul, London.

Marsh, D. C. (1964). The Future of the Welfare State. Penguin Books, Harmondsworth, Middlesex.

Morris, G. E. (1954). Arch. industr. Hyg., 10, 43.

\title{
Effect of Antibiotic Treatment on Duration of Excretion of Salmonella typhimurium by Children
}

\author{
J. M. S. DIXON,* M.D., M.C.PATH., DIP. BACT.
}

Brit. med. F., 1965, 2, 1343-1345

Salmonellae may be present in the faeces for some weeks or months after patients have clinically recovered from gastroenteritis. Treatment with antibiotics to which the organism has been shown to be sensitive in vitro often. fails to eradicate the organism from these symptomless excreters. Furthermore, there has been a suggestion that antibiotic treatment may lengthen the period of excretion ; Szanton (1957), who studied infants infected with Salmonella oranienburg, reported that patients given antibacterial treatment excreted the organism for a longer period than those who were untreated. If similar observations are forthcoming, strong support would be given to the view that excreters of salmonellae, whether suffering from diarrhoea or not, should not be given specific antibiotic therapy (Taylor, 1963).

In this paper a comparison is made between the duration of excretion of Salm. typhimurium by schoolchildren in two outbreaks in which faeces specimens from every infected child were examined regularly until excretion ceased. In one incident, which occurred in Suffolk in 1964, 63 (94\%) of the 67 infected children were treated with antibiotics to which the organism was sensitive in vitro ; in the other, which occurred in South

- Wales in 1954 and was reported by Lennox, Harvey, and Thomson (1954), most of the 64 children who were infected received no antibacterial treatment. Apart from the fact that the children in only one of the outbreaks were given specific treatment, the two incidents were remarkably similar. Advantage has been taken of this similarity to assess the effect of the antibiotic treatment on the duration of excretion of Salm. typhimurium by the Suffolk children.

* Public Health Laboratory, Ipswich.

\section{The Outbreaks}

\section{A. Suffolk, 1964 ; Most Children Given Antibiotics}

In September 1964 an outbreak of food-poisoning caused by Salm. typhimurium phage-type $2 \mathrm{a}$ occurred at a school in Suffolk. It is believed that the vehicle of infection was a pork pie served at a school lunch ; 67 children ate the pie and all developed gastro-enteritis. The children, who were between 5 and 11 years of age, were attended by their own general practitioners. Faeces specimens from each child were examined at intervals of a week or less until three consecutive negative results had been reported.

The 14 general practitioners concerned kindly provided details of the treatment given to $65(97 \%)$ of the infected children. A total of 103 courses of preparations containing antibacterial drugs were given to 63 children-29 children had one course, 28 had two courses, and 6 had three courses. Some of the preparations given had more than one antibacterial constituent, such as an antibiotic and a sulphonamide drug. Antibiotics to which the salmonella was sensitive in vitro were given to 63 children; 41 had one course, 21 had two courses, and one had three. The numbers of children given each antibiotic were: neomycin, 39 ; streptomycin, 21 ; ampicillin, 14 ; tetracycline, 8 ; and chloramphenicol, 4 . In addition, 48 children were given sulphonamide treatment, generally in combination with an antibiotic. The great variety of preparations that were used makes it impossible for more precise details to be given, but the dosages prescribed were those currently recommended for the treatment of bacterial gastro-enteritis. Courses of treatment were of at least five days' duration. 


\section{B. Wales, 1954 ; Most Children Not Given Antibiotics}

In February 1954 an outbreak of infection with Salm. typhimurium occurred at a school in South Wales; the details were reported by Lennox et al. (1954). The vehicle of infection was thought to be unpasteurized milk. Sixty-four children between 5 and 10 years of age became ill, and "only a handful" of them were given chloramphenicol or any other antibacterial drug. Faeces specimens were collected twice weekly from all the children until they became free from infection.

\section{Methods}

The bacteriological methods used for the examination of specimens from the two outbreaks were almost identical. Selective agars were inoculated both directly with faeces and also after enrichment of the specimen in selenite $\mathrm{F}$ broth. The main reason for the remarkable similarity of the techniques is that in 1954 I was on the staff of the Cardiff Public Health Laboratory, where specimens from the Welsh outbreak were examined, and since my transfer to Ipswich I have used the same techniques as those practised in Cardiff. Thus it is possible to state that the techniques used for specimens from children in both outbreaks were so similar that it is unlikely that there was any significant difference in sensitivity between them.

Strains of Salm. typhimurium from eight of the children in the Suffolk outbreak were kindly examined by Dr. E. S. Anderson at the Enteric Reference Laboratory, Colindale, London, and were reported to belong to phage-type 2a. Sensitivity to drugs was determined by a diffusion method on blood agar, paper disks containing the following amounts of drugs being used: sulphafurazole, $500 \mu \mathrm{g}$. ; streptomycin, $25 \mu \mathrm{g}$. ; tetracycline, $50 \mu \mathrm{g}$. ; chloramphenicol, $50 \mu \mathrm{g}$. ; neomycin, $30 \mu \mathrm{g}$. ; and ampicillin, $25 \mu \mathrm{g}$. The tests with sulphafurazole were performed with small inocula on lysed horse-blood agar (Harper and Cawston, 1945).

\section{Results}

From the 67 children infected at the Suffolk school 623 faeces specimens were examined. The number of children with positive faeces at weekly intervals after infection is shown in the Table. Very few children ceased to excrete the organism in the first four weeks; thereafter there was a steady diminution in the number remaining positive, until at the eighteenth week all were free from infection. Fifteen strains of Salm. typhimurium, chosen at random and isolated before the children were treated, were tested for sensitivity to drugs; all were found to be sensitive to streptomycin, neomycin, tetracycline, ampicillin, and chloramphenicol, but resistant to sulphonamides. Strains isolated in the twelfth week after infection from the nine children who were still excreting the organism were also tested; eight strains gave results identical to those of the strains isolated before treatment, but one was resistant to tetracycline.

The results of the examination of faeces specimens from the Welsh children quoted by Lennox et al. (1954) are also given in the Table. The duration of their excretion of the pathogen was clearly shorter than that of the Suffolk children. The results are further compared in the Chart, in which, in addition to the results of the full enrichment examination of specimens from the Suffolk (curve A) and Welsh (curve B) children, a third curve $(C)$ indicates the results of the faeces of the Suffolk children when examined by a much less sensitive techniquenamely, by the omission of enrichment in selenite $F$ and reliance solely on direct plating on deoxycholate citrate agar. It is seen that even by the use of this relatively insensitive cultural technique the Suffolk children were found to excrete the salmonella for a longer period than the Welsh children. There was no source from which the Suffolk children might have been reinfected, and the pathogen must have persisted in the intestine from the time of infection at the school meal.

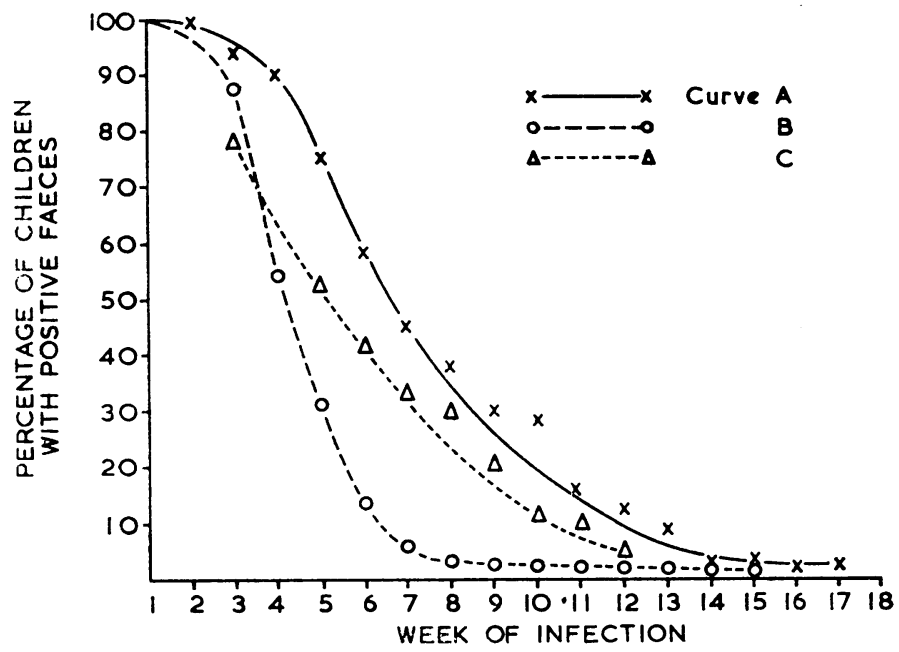

Duration of excretion of Salm. typhimurium in the faeces of children infected in two outbreaks. Curve A, treated children (Suffolk); Curve B, untreated children (Wales); curve C, Suffolk children examined by less sensitive techniques.

\section{Discussion}

The duration of the period during which salmonellae are excreted after clinical recovery from gastro-enteritis is variable, being longest in infants (Rubenstein, Feemster, and Smith, 1944), but is measured in weeks or months rather than years. The epidemiological importance of this short period of excretion is quite different from that of the carrier state that sometimes occurs after enteric fever, when typhoid bacilli may be excreted for the remainder of the patient's life. Because spontaneous clearance of Salm. typhimurium infection may occur at any time, studies of the effect of antibiotics on the duration of excretion of the organisms should not be confined to patients who do not become free from infection as rapidly as the majority, but should be made on complete populations of infected persons; if those who became clear rapidly were omitted it would be difficult to demonstrate any prolongation of the period of excretion that occurred as a result of treatment. Faeces specimens from persons infected in outbreaks would be suitable material for comparative purposes if specimens from every infected person were examined regularly until repeatedly negative. It would be possible to make an evaluation of anti-

Number and Percentage of Children whose Faeces Harboured Salm. typhimurium at Weekly Intervals after Infection in Two Outbreaks

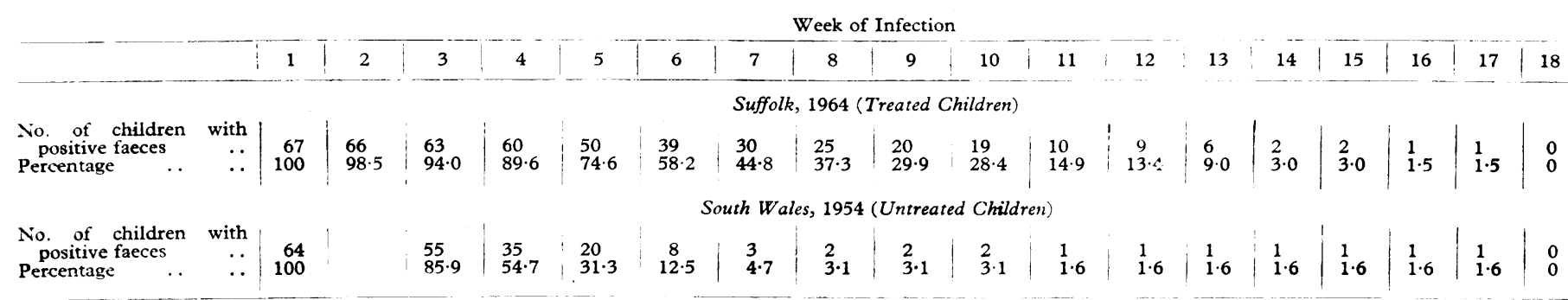


biotic treatment if the only difference between two such outbreaks was that patients in one were given specific treatment, whereas those in the other were untreated.

Such comparable outbreaks do not commonly occur, but the two reported here are thought to be sufficiently similar for a conclusion to be drawn from a comparison of them. The points of similarity were: the infecting organism in each incident was Salm. typhimurium; both outbreaks occurred in non-residential schoolchildren of 5 to 11 years of age; the number of infected children in each was known; faeces specimens from all the children infected were examined at regular intervals, weekly or less, until three negative results were reported; and the outbreaks were similar in size-64 children in one, and 67 in the other. The differences, apart from the obvious ones of time and place, were that $94 \%$ of the Suffolk children but only a few of the Welsh children were treated; that the strains of infecting organism were probably different; and that although the laboratory techniques used were very similar they may not have been of identical sensitivity. However, as the duration of excretion by the Suffolk children was shown to exceed that of the Welsh children even when a relatively insensitive cultural technique was used for specimens from the former group, the differences in laboratory technique can probably be largely discounted. The effect of strain differences is unknown, but in view of the number of comparative investigations that are based, without obvious discrepancies, on studies of different strains of Salm. typhimurium they are probably not of major importance. Thus the only obvious difference between the outbreaks is the antibacterial treatment given to almost all the Suffolk children.

The mechanism whereby the intestine frees itself of salmonella organisms is not clear. Studies in animals suggest that in the small intestine bacteria are propelled onwards rapidly to the caecum by peristaltic action (Dixon, 1960) and that salmonellae behave similarly to other organisms in this respect (Miller and Bohnhoff, 1962). In the caecum and large intestine of mice there is evidence of bacteriostatic or weakly bactericidal activity against salmonellae (Meynell and Subbaiah, 1963). This is probably due largely to volatile fatty acids produced by the activity of the normal bacterial flora (Meynell, 1963); when the normal flora, in which anaerobic bacilli predominate, was eliminated by the oral administration of streptomycin, the concentration of fatty acids fell and the antibacterial activity ceased. This suggestion that the normal flora plays an important part is supported by the observation that oral administration of streptomycin increases the susceptibility of mice to infection with salmonellae (Bohnhoff and Miller, 1962). The increased susceptibility was' studied by Miller and Bohnhoff (1963), who thought it was related chiefly to the elimination from the intestine of Bacteroides species, and reported that some strains of these anaerobic bacilli inhibited the growth of salmonellae in vitro. The elimination from the intestine of Escherichia coli, which occurred concurrently, was apparently not a significant factor.

Many antibiotics, given singly or in combination, have been used in attempts to eliminate salmonellae from the intestine after gastro-enteritis. Unfortunately no more success has been achieved with recently introduced drugs such as paromomycin (Coles and Stewart, 1961) and ampicillin (Stewart, Coles, Nixon, and Holt, 1961), despite the value of the latter in the treatment of typhoid carriers (Christie, 1964), than with those previously available (Lancet, 1959). Failure of treatment is not generally associated with the development by the organisms of resistance to the unsuccessful antibiotic. It is difficult to explain the persistence of salmonellae during treatment with large doses of poorly absorbed bactericidal drugs such as neomycin and paromomycin, but the experimental evidence that has been quoted suggests that such therapy might eradicate those constituents of the normal flora of the large gut which are concerned with the natural clearance mechanism. The re-establishment of the normal flora may be an important mechanism in clearing the gut of foreign bacteria.
Unfortunately no drug is available which will kill salmonellae without injuring the normal flora, but efforts have been made to supplement antibiotic therapy with doses of antibioticresistant bacterial suspensions in an attempt to replace the organisms that are killed. Doyle (1960) reported that a combination of tetracycline and lactobacilli gave promising results in the few patients he studied. Stewart, Holt, Coles, and Bhat (1964) treated five babies who were excreting Salm. typhimurium. They gave them neomycin or paromomycin together with autogenous strains of $E$. coli that they had trained to be resistant to $200 \mu \mathrm{g}$. of the antibiotic per $\mathrm{ml}$. The pathogen was eliminated from only two of the infants. However, since the concentration of these unabsorbed antibiotics in the bowel contents may have been higher than that to which the $E$. coli strains were resistant, it is possible that the coliforms may not have survived long enough to play a significant part.

The results of the present study suggest that antibiotic treatment prolonged the period of faecal excretion of Salm. typhimurium ; they are in accordance with the observations of Szanton (1957), who noted that treated infants excreted a salmonella strain for longer than those who were untreated. The treatment given to the Suffolk children was so varied that no comment can be made on the effect of any particular preparation or antibiotic. Rarely, except in infants, will Salm. typhimurium be excreted in the faeces for more than two or three months, and it may be unwise to interfere by the administration of potent and possibly toxic drugs with what may be the most effective mechanism yet available whereby salmonellae are eliminated from the gut-the antagonistic action of bacteria that are normally present in the large intestine.

\section{Summary}

Of 67 children infected in an outbreak of food-poisoning due to Salm. typhimurium $63(94 \%)$ were treated with antibiotics to which the strain was sensitive in vitro. The duration of excretion of the organism in the children's faeces was studied and compared with that of untreated children in an otherwise similar outbreak reported in 1954. Antibiotic treatment did not shorten the period of symptomless excretion of the salmonella organisms but may have prolonged it, perhaps by interference with the normal clearance mechanism.

I gratefully acknowledge the assistance given me by Dr. K. M. Harding, the medical officer of health for the area, and her public health inspectors, especially Mr. L. W. Brown, who arranged for the collection of many of the specimens. I am indebted to the following general practitioners who so kindly co-operated by sending me details of the treatment they gave: Drs. G. R. Bernard, R. Brown, D. S. Cooke, H. A. Frazer, I. P. Granger, J. Harper, C. G. Harrison, C. A. Hutt, R. U. F. Kynaston, E. O. Lawton, A. D. Lower, D. M. Rahilly, A. J. Russell, and N. Stevens. My thanks are also due to Professor Scott Thomson and members of the staff of the Cardiff Public Health Laboratory for providing unpublished information about the Welsh outbreak.

\section{REFERENCES}

Bohnhoff, M., and Miller, C. P. (1962). F. infect. Dis., 111, 117.

Christie, A. B. (1964). Brit. med. F., 1, 1609.

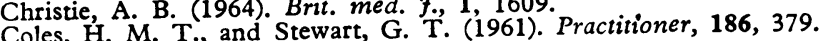

Coles, H. M. T., and Ste Path. Bact., 79, 131.

Dixon, J. S. (1960) Lancet, 1 1073

Doyle, J. S. (1960). Lancet, 1, 1073. (1945). 7. Path. Bact., 57, 59.

Harper, G. J., ¿nd Caws

Lancet, 1959, 2, 501. . W. S., and Thomson, S. (1954). F. Hyg. (Camb.), Lennox, M.,

52, 311. G. (1963). Brit. 7. exp. Path., 44, 209.

Meynell, G. G. (1963). Brit. 7. exp. Path., 44,

Miller, and Subbaiah, T. V. (1963). Ibid., 44, 197.

Miller, C. (1963). Ibid., 113, 59.

Rubenstein, A. D., Feemster, R. F., and Smith, H. M. (1944). Amer

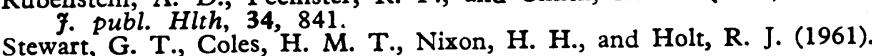

Brit. med. F., 2, 200 . H. M. T., and Bhat, K. M. (1964). F. Hyg., (Camb.), 62, 39.

zzanton, V. L. (1957). Pediatrics, 20, 794.

Szanton, (1963). In Infection in Hospitals : Epidemiology and Control, edited by R. E. O. Williams and R. A. Shooter, p. 152. Blackwell, Oxford. 